\title{
Relationship between photosynthesis, bleeding-sap mass, and bleeding components in maize hybrids and corresponding parents in northern China
}

\author{
Z. HE, C. XU, B. LIU, B. YAO, H. WANG, Z.Y. CHEN, D.Y. LI, Z.Y. BAI, and Z.A. ZHANG \\ Department of Agronomy, Jilin Agricultural University, 130118 Changchun, Jilin Province, China
}

\begin{abstract}
Currently, the main maize production areas in northeastern China are facing soil fertility loss, which severely affects root growth and limits photosynthesis. It is widely acknowledged that physiological conditions of the root system are closely related to the photosynthetic capacity; therefore, we evaluated whether there are certain differences in root bleeding sap characteristics and photosynthetic capacity between the hybrids and their parents. The results showed that heterosis of the photosynthetic capacity occurred at the milk-ripe stage; however, heterosis of bleeding-sap mass (BSM) and organic biomass occurred during the whole growth period. Photosynthetic rate correlated positively with BSM and the bleeding components; a similar trend was also observed between BSM and bleeding components. These data suggested that appropriate water and fertilizer supply can improve the photosynthesis-related parameters and yield of maize.
\end{abstract}

Additional key words: bleeding-sap intensity; filling stage; hundred-grain mass; net photosynthetic rate; silking stage; Zea mays.

\section{Introduction}

The steady increase of the yield of maize (Zea mays L.) in China over the past 45 years has been achieved. One of the reasons was the wide-ranging application of heterosis since the 1970s (Zhou 2000). Nowadays, maize has become the most important cereal crop (Li et al. 2016) and its yield has increased to more than one third of gross grain production in China (FAO 2016). Numerous studies had been already reported about maize hybrids, focusing on agronomic traits and physiological character of heterosis compared to inbred lines (Cirilo et al. 2009, Paschold et al. 2010, Chairi et al. 2015). All the genetic improvement and high yield cultivation technologies are contributing to the improvement of the photosynthetic capacity and root physiological activity under a suitable state of growth (Karmakar and Bhatnagar 1996, Specht et al. 1999, Wilcox 2001). Li et al. (2012) showed that the specific leaf mass, chlorophyll (Chl) content, and net photosynthetic rate $\left(P_{\mathrm{N}}\right)$ of high-yield varieties were higher than those of lowyield varieties. Therefore, the level of photosynthesis is an important index to regulate the maize yield, and hybrids tend to have higher photosynthetic rates and yields than inbred lines (Haque et al. 2015).

It is well known that there is a close coordination between the leaf and root, with the root system providing water and ions for the aboveground parts of the plant to promote growth and development (Guan et al. 2014), while leaves in turn provide photosynthates with sufficient energy for roots. However, Koester et al. (2016) and Li et al. (2016) considered that the photosynthetic capacity of recently released cultivars may not be improved under adverse conditions. One of the important factors was a root restriction that often depresses photosynthetic capacity (Shi et al. 2008), especially, reduction of root adsorbates from a growth environment. At the same time, bleeding sap is a link that connects the leaves and roots. Several studies documented that bleeding sap was significantly positively correlated with root dry mass and root vigor (Dieleman et al. 1998, Kato et al. 2001, Cui et al. 2016). These studies implied that bleeding sap may be used as an effective index of physiological characteristics of the roots, therefore, bleeding sap and bleeding components play critical role in leaf photosynthetic capacity and aboveground characteristics. However, it was rarely reported that the photosynthetic capacity was revealed from bleeding sap and bleeding components, and heterosis was discussed including $P_{\mathrm{N}}$ and bleeding-sap mass. It is thus necessary to clarify whether bleeding sap and bleeding components are related to photosynthesis, and its changes caused by heterosis.

In this study, we evaluated whether the photosynthetic rate significantly correlates with bleeding-sap mass or bleeding components, and compared the difference of bleeding-sap mass and organic biomass of hybrids and their parents. Finally, we aimed to verify if the root bleeding intensity positively correlates with bleeding components and organ biomass and reflects the mutual coordination between the roots and leaf organs of hybrids and their parents.

\footnotetext{
$\overline{\text { Received }} 9$ August 2018, accepted 13 December 2018.

${ }^{+}$Corresponding author; phone, fax: + 86-431-84532849, e-mail: zhangzhian6412@163.com

Abbreviations: BSM - bleeding-sap mass; DMP - dry matter per plant; FP - female parent; HGM - hundred-grain mass; LS - leaf sheath; MP - male parent; $P_{\mathrm{N}}$ - net photosynthetic rate; R1 - silking stage; R2 - filling stage; R3 - milk-ripe stage; V6 - jointing stage. Acknowledgements: This study was supported by the National Natural Science Foundation of China (Grant No. 31171459) and the Jilin Province Science and Technology Development Plan Major Project (Grant No. 20126033).
} 


\section{Materials and methods}

Plant materials and field experiments: Three maize hybrids, which are widely cultivated in Jilin Province, and their corresponding parents, were selected for this study. The first group was Xianyu335 (hybrid), PH4CV (male parent), PH6WC (female parent); the second group was Liangyu99 (hybrid), M5972 (male parent), MO3 (female parent); and the third group was Tiannong9 (hybrid), W08 (male parent), and T106 (female parent). These experimental cultivars had a similar growth duration. The seeds were provided by the Maize Research Institute of Jilin Agricultural University.

The experiment was conducted in 2015 at the experimental station of the Jilin Agricultural University, located in Changchun, Jilin, China $\left(43^{\circ} 31^{\prime} \mathrm{N}, 125^{\circ} 6^{\prime} \mathrm{E}\right)$. Initial soil characteristics at the experimental site were as follows: $27.4 \mathrm{~g}$ (soil organic matter content) $\mathrm{kg}^{-1}, 1.65 \mathrm{~g}$ (total nitrogen) $\mathrm{kg}^{-1}, 0.86 \mathrm{~g}$ (total phosphorus) $\mathrm{kg}^{-1}, 0.12 \mathrm{~g}$ (alkali-hydrolysable nitrogen) $\mathrm{kg}^{-1}, 26.9 \mathrm{mg}$ (available phosphorus) $\mathrm{kg}^{-1}, 122 \mathrm{mg}$ (available potassium) $\mathrm{kg}^{-1}$, and soil $\mathrm{pH}$ 6.8. The field soil had a loamy texture and was mainly rotated with soybeans and maize. For this region, precipitation was $645 \mathrm{~mm}$ from May to October 2015, the accumulated temperature $\left(\geq 10^{\circ} \mathrm{C}\right)$ was $2,880^{\circ} \mathrm{C}$, the annual average temperature was $4.8^{\circ} \mathrm{C}$, and the frost-free period was about $140 \mathrm{~d}$ (data provided by weather stations of Jilin province).

The experiments were arranged in a completely randomized block design with three replications. Two plots were planted with cultivars, each cultivar had 12 rows, and row length and row spacing of each plot was $5 \mathrm{~m}$ and $0.65 \mathrm{~m}$, respectively. All experimental cultivars were sowed on 29 April 2015 using a spacing-adjusted seeder for hill seeding at a distance of $25 \mathrm{~cm}$. All varieties were finally singled out at the seedling stage to a density of 61,500 plants $\mathrm{ha}^{-2}$. Weeds, diseases, and insects were intensively controlled throughout the entire growth period with herbicide, insecticide, and manual management. We selected three representative plants and set up four individual sampling dates throughout the growing season at the jointing stage (V6), the silking stage (R1), the filling stage (R2), and the milk-ripe stage (R3), during which leaf photosynthetic parameters were measured and bleedingsap samples were collected and analyzed.

Net photosynthetic rate: Leaf photosynthetic parameters were measured using a $L i-6400 X T$ portable photosynthesis system (Li-Cor Inc., Lincoln, NE, USA) from 9:00-11:30 h. The upper third leaf (the third fully unfolded leaf from the top of the main stem) of three representative plants was measured at V6, while the leaf position was obtained for the measurement transfer to ear leaf at R1, R2, and R3. Using the LI-6400-02B artificial light source control, the light intensity was set to $1,800 \mu \mathrm{mol}$ (photon) $\mathrm{m}^{-2} \mathrm{~s}^{-1}$ (lightsaturation point for maize cultivars). The overall environmental factors of the photosynthetic index showed small differences throughout the entire growth period; the temperature was $33.6 \pm 1.83^{\circ} \mathrm{C}$, the relative humidity was $48.3 \pm$ $5.2 \%$, and PPFD was $1,457 \pm 121 \mu \mathrm{mol}$ (photon) $\mathrm{m}^{-2} \mathrm{~s}^{-1}$.
Bleeding-sap mass (BSM): Three plants under the same growth conditions were selected and were used to collect bleeding sap by cutting at the position of $5 \mathrm{~cm}$ of the stem and using distilled water and absorbent paper to deal with plant incision. The first droplets were discarded to prevent contamination of the bleeding sap. Absorbent cotton, a polyethylene bag, and a rubber band were prepared to collect bleeding sap of xylem, and its mass was beforehand recorded as W1 (g). The absorbent cotton of each duplication was removed after $2 \mathrm{~h}$, and the mass was recorded as W2 $(\mathrm{g})$. The procedure was always repeated every two hours and the collection time lasted $24 \mathrm{~h}$ from 5:00 h till 5:00 h of the next day. The average of 24-h bleeding sap was used for this study. The equation was as follows: BSM $\left[\mathrm{g} \mathrm{h}^{-1}\right.$ plant $\left.^{-1}\right]=(\mathrm{W} 2-\mathrm{W} 1) / 2$.

Bleeding components: After the collection, the bleeding sap was placed in a 2-ml centrifuge tube. The measurement methods were as follows: soluble sugar was measured using the anthrone method (Yemm and Willis 1954), the soluble protein using the Coomassie Brilliant Blue G-250 dyeing method (Sedmak and Grossberg 1977), the free amino acid content using the ninhydrin staining method (Moore and Stein 1954), ammonium nitrogen using the indophenol blue spectrophotometric method (van Staden and Taljaard 1997), nitrate nitrogen using the ultraviolet spectrophotometry method (Bao 2011). These data were measured by the TU1901 UV-visible spectrophotometer ( $P G$ Scientific, USA); mineral ions including $\mathrm{K}, \mathrm{Ca}, \mathrm{Mg}$, $\mathrm{Fe}, \mathrm{Mn}, \mathrm{Zn}$, and $\mathrm{Cu}$ were measured using the AA800 atomic absorption spectrometer (PerkinElmer Inc., USA).

Organ biomass: After the collection ofbleeding sap, the aboveground parts of plants were sepa-rated into four parts: stem, leaf, leaf sheath, and ear. Ears were hand-threshed, and 100 seeds were randomly selected. Organ biomass of different organs was determined after oven drying at $80^{\circ} \mathrm{C}$ to a constant mass. All parts of the organ biomass were added to obtain the dry matter per plant.

Data analysis: The experimental results were average data of three replicates under the randomized complete block design. The data were subjected to analysis of variance (ANOVA) and correlation analysis via SPSS 13.0 (SPSS Inc., Chicago, USA). Means of photosynthetic parameters and bleeding sap were subjected to the least significant difference (LSD) test at the $p<0.05$ level. Pearson's double variables and partial correlation analysis between bleeding sap and photosynthetic parameters were determined.

\section{Results}

Organ biomass, photosynthetic rate, bleeding-sap mass, and bleeding components: The bleeding-sap component (BSM), $P_{\mathrm{N}}$, and organ biomass were measured at V6, R1, $\mathrm{R} 2$, and R3 stages, and the differences between the male parent, female parent, and corresponding hybrids were compared (Table 1, Figs. 1, 2). The organ biomasses were calculated as the average value of the male parents, female parents, and corresponding hybrids (Table 1). There was 
no difference in organ biomass between the male parent and female parent; however, significant differences were observed in hybrids compared to corresponding parents at different stages (male parent and female parent). The biomass of stem, leaf, and leaf sheath (vegetative organs) reached a maximum at the $\mathrm{R} 2$ stage, while the biomass of the ear, hundred-grain mass (HGM), and dry mass per plant (DMP) gradually increased during the growth stages. Since biomass of vegetative organs decreased after the R2 stage, the growth rate of the biomass of ear, HGM, and DMP increased significantly after R2 compared to other stages (Table 1 ). The $P_{\mathrm{N}}$ of hybrids showed no significant difference in comparison with corresponding parents at V6, R1, and R2, but showed a significant difference at R3. There was a significant difference between hybrids and parents in BSM in each of the growth stages. As the growth period progressed, photosynthetic rate and BSM decreased except for T106 and Tiannong9 (Table 2). The contents of each bleeding component are shown in Fig. 2, revealing different trends at different stages. There was a small difference between hybrids and parents for physiological indexes (except for mineral elements) at different stages, however, mineral elements differed significantly.

Correlation between $\boldsymbol{P}_{\mathrm{N}}, \mathrm{BSM}$, and bleeding components: The $P_{\mathrm{N}}$ had a close correlation with BSM and bleeding components at growth stages for three cross combinations (Figs. 3, 4). As illustrated in the linear regression (Fig. 3), the $P_{\mathrm{N}}$ was positively correlated with BSM. In addition, similar tendencies were also observed between

Table 1. Changes of biomass of aboveground organs among male parents (MP), female parents (FP), and corresponding hybrids (FP $\times$ MP). DMP - dry matter per plant; HGM - hundred-grain mass; LS - leaf sheath; R1 - silking stage; R2 - filling stage; R3 - milk-ripe stage; V6 - jointing stage. Different lowercase letters in the same column indicate significant differences at the 0.05 level.

\begin{tabular}{|c|c|c|c|c|c|c|c|}
\hline \multirow[t]{2}{*}{ Genetic relationship } & \multirow[t]{2}{*}{ Growth stage } & \multicolumn{6}{|c|}{ Biomass of above-ground organs [g] } \\
\hline & & Stem & Leaf & LS & Ear & HGM & DMP \\
\hline \multirow[t]{4}{*}{ MP } & V6 & $3.1 \pm 0.8^{\mathrm{e}}$ & $10.9 \pm 0.7^{\mathrm{e}}$ & $3.4 \pm 0.4^{\mathrm{f}}$ & - & - & $17.4 \pm 1.9^{\mathrm{f}}$ \\
\hline & $\mathrm{R} 1$ & $34.0 \pm 1.1^{\mathrm{c}}$ & $26.2 \pm 0.3^{b c}$ & $15.4 \pm 1.2^{\mathrm{de}}$ & $8.6 \pm 0.7^{\mathrm{f}}$ & - & $84.2 \pm 2.6^{\mathrm{cd}}$ \\
\hline & $\mathrm{R} 2$ & $41.3 \pm 1.7^{\mathrm{bc}}$ & $28.3 \pm 1.1^{\mathrm{b}}$ & $17.3 \pm 0.5^{\text {cde }}$ & $33.3 \pm 1.4^{\mathrm{d}}$ & - & $120.1 \pm 4.3^{c}$ \\
\hline & $\mathrm{R} 3$ & $37.1 \pm 3.0^{\mathrm{c}}$ & $25.1 \pm 1.4^{\mathrm{bc}}$ & $14.9 \pm 1.5^{\text {de }}$ & $81.1 \pm 1.6^{\mathrm{b}}$ & $9.4 \pm 1.7^{\mathrm{b}}$ & $211.3 \pm 6.6^{\mathrm{b}}$ \\
\hline \multirow[t]{4}{*}{ FP } & V6 & $3.3 \pm 1.6^{\mathrm{e}}$ & $12.8 \pm 0.3^{\mathrm{e}}$ & $4.2 \pm 0.5^{\mathrm{f}}$ & - & - & $20.3 \pm 2.0^{\mathrm{f}}$ \\
\hline & $\mathrm{R} 1$ & $30.8 \pm 1.6^{\mathrm{c}}$ & $33.7 \pm 1.9^{\mathrm{b}}$ & $20.8 \pm 0.7^{\mathrm{bcd}}$ & $4.7 \pm 0.6^{\mathrm{f}}$ & - & $89.9 \pm 1.2^{\mathrm{cd}}$ \\
\hline & $\mathrm{R} 2$ & $37.8 \pm 0.4^{\mathrm{c}}$ & $27.7 \pm 6.0^{\mathrm{b}}$ & $14.9 \pm 4.0^{\mathrm{de}}$ & $23.5 \pm 1.2^{\mathrm{de}}$ & - & $103.9 \pm 10.3^{\mathrm{c}}$ \\
\hline & $\mathrm{R} 3$ & $40.6 \pm 4.6^{\mathrm{bc}}$ & $35.2 \pm 3.9^{\mathrm{b}}$ & $21.5 \pm 2.6^{\mathrm{bcd}}$ & $62.0 \pm 2.5^{\mathrm{c}}$ & $9.9 \pm 0.1^{\mathrm{b}}$ & $210.5 \pm 16.7^{b}$ \\
\hline \multirow[t]{4}{*}{$\mathrm{FP} \times \mathrm{MP}$} & V6 & $14.0 \pm 0.9^{d}$ & $25.0 \pm 3.1^{\mathrm{bc}}$ & $9.6 \pm 1.2^{\mathrm{ef}}$ & - & - & $48.6 \pm 5.0^{\mathrm{e}}$ \\
\hline & $\mathrm{R} 1$ & $41.4 \pm 3.5^{\mathrm{bc}}$ & $47.4 \pm 3.5^{\mathrm{a}}$ & $24.9 \pm 1.3^{\mathrm{abc}}$ & $13.9 \pm 1.1^{\mathrm{ef}}$ & - & $127.6 \pm 7.6^{c}$ \\
\hline & $\mathrm{R} 2$ & $57.6 \pm 4.2^{\mathrm{b}}$ & $52.2 \pm 3.5^{\mathrm{a}}$ & $28.1 \pm 2.5^{\mathrm{ab}}$ & $62.9 \pm 6.4^{c}$ & - & $200.9 \pm 16.4^{b}$ \\
\hline & $\mathrm{R} 3$ & $77.1 \pm 10.7^{\mathrm{a}}$ & $53.4 \pm 3.8^{\mathrm{a}}$ & $31.5 \pm 3.1^{\mathrm{a}}$ & $147.2 \pm 6.0^{\mathrm{a}}$ & $15.5 \pm 1.0^{\mathrm{a}}$ & $399.6 \pm 24.2^{\mathrm{a}}$ \\
\hline
\end{tabular}

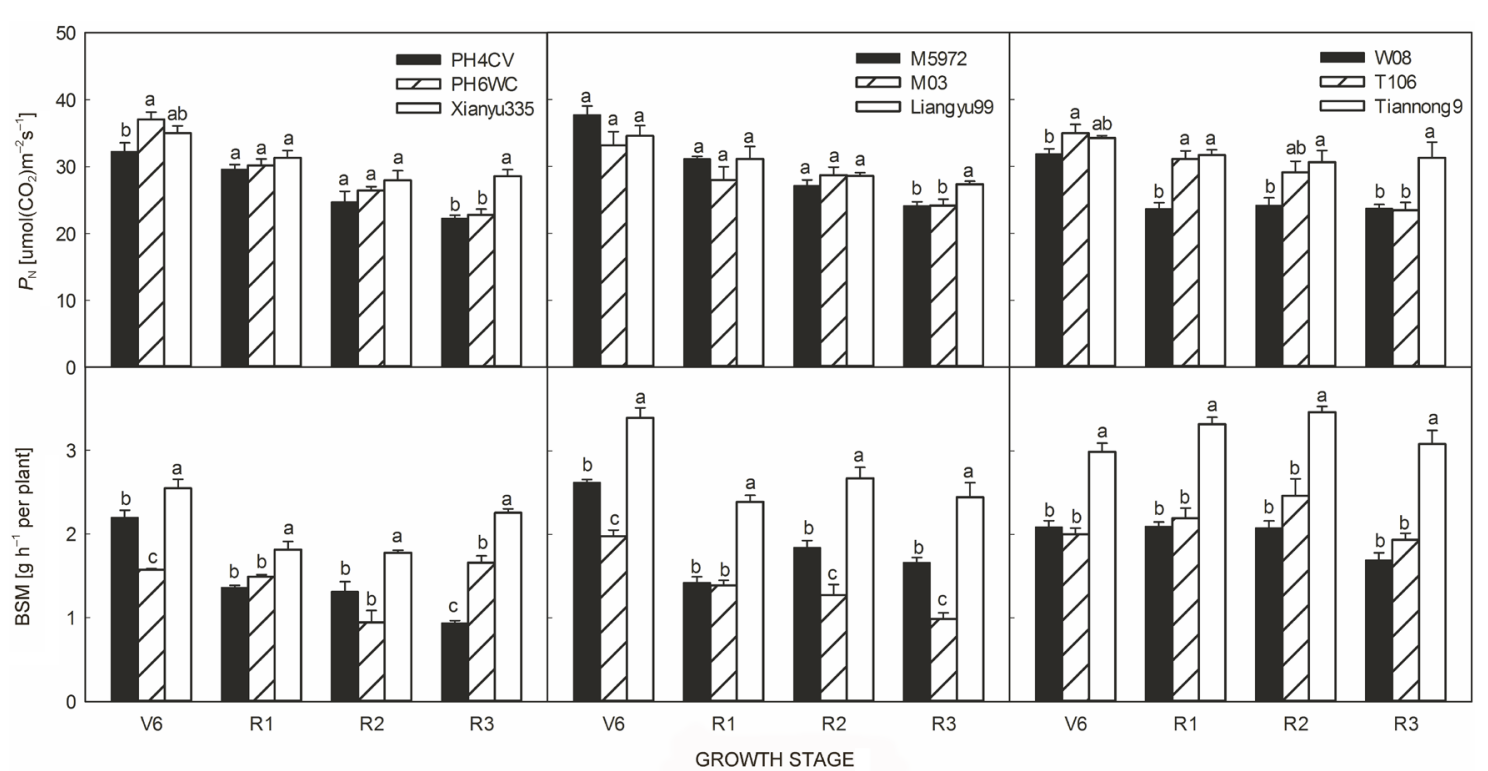

Fig. 1. Changes of net photosynthetic rate $\left(P_{\mathrm{N}}\right)$ and bleeding-sap mass $(\mathrm{BSM})$ at different growth stages for three cross combinations. V6 - jointing stage; R1 - silking stage; R2 - filling stage; R3 - milk-ripe stage. Different lowercase letters at the same stages indicate significant differences at the 0.05 level. 

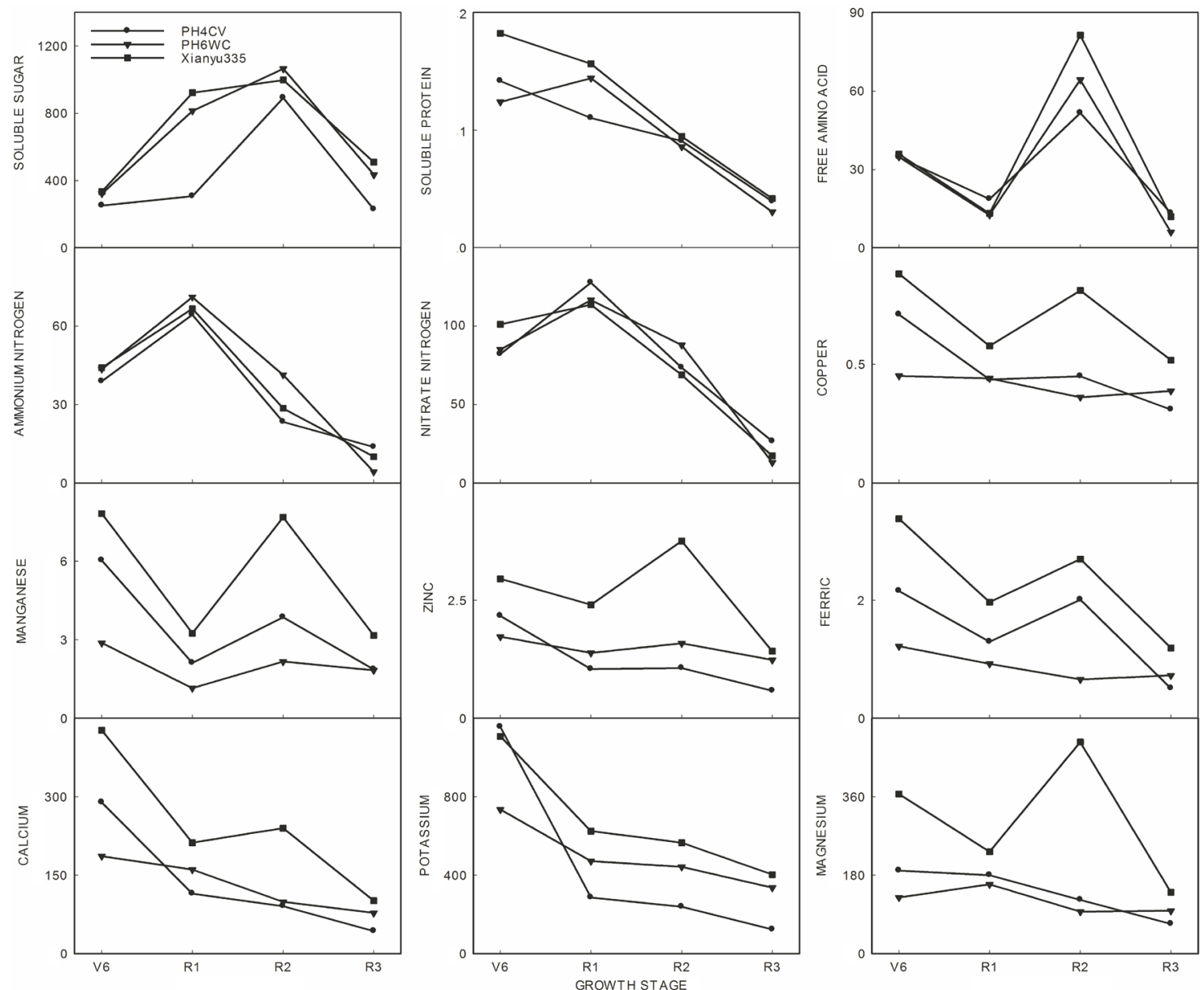

Fig. 2. Changes of bleeding components at different growth stages for three cross combinations. Unit: $\mu \mathrm{g}\left(\right.$ component) $\mathrm{g}^{-1}$ (bleeding sap). V6 - jointing stage; R1 - silking stage; R2 - filling stage; R3 - milk-ripe stage.

$P_{\mathrm{N}}$ and bleeding components except for copper ion, which had no significant relationship with $P_{\mathrm{N}}$.

Correlation between BSM, bleeding components, and organ biomass: The BSM of three cross combinations showed a different correlation with bleeding components and organ biomass (Table 2). BSM revealed a significant positive correlation with mineral elements and organ biomass. In contrast, correlations between BSM and nitrogen assimilates were weak.

\section{Discussion}

Photosynthesis is the physiological basis for crop yield formation, and to some extent, the intensity of photosynthesis determines the level of crop production (Muchow and Davis 1988, Wang et al. 2016). Numerous studies have shown that maize hybrids have an advantage of higher photosynthetic and yield performance than that of the corresponding parents (Cirilo et al. 2009, Paschold et al. 2010, Chairi et al. 2015). The present study showed that maize heterosis for photosynthesis had significant differences at the R3 stage, but no significant differences at V6, R1, or R2 stages. Interestingly, organ biomass of hybrids had apparent heterosis from the jointing stage to mature period for maize. In general, there are many factors that increase crop yield, but the most important point is to increase the physiological activity of roots. Physiological state of roots is the fundamental assurance of the efficient photosynthetic rate in the leaves (Kimura et al. 1999, Chen 2016), and photosynthesis is inhibited when the conditions are not favorable for root growth (Shi et al. 2008). Root physiological status may affect photosynthesis and

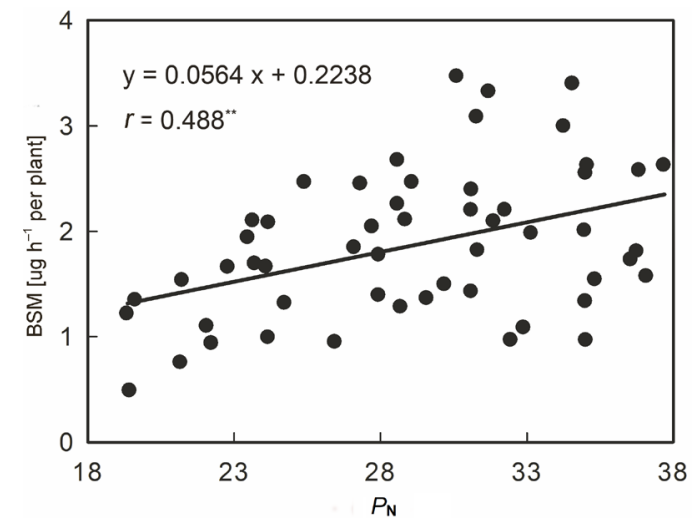

Fig. 3. Correlation between photosynthetic rate $\left(P_{\mathrm{N}}\right)$ and bleedingsap mass (BSM) among three cross combinations. ${ }^{* *}$ - indicate significant correlation between BSM and $P_{\mathrm{N}}$ at $p<0.01$ level. 

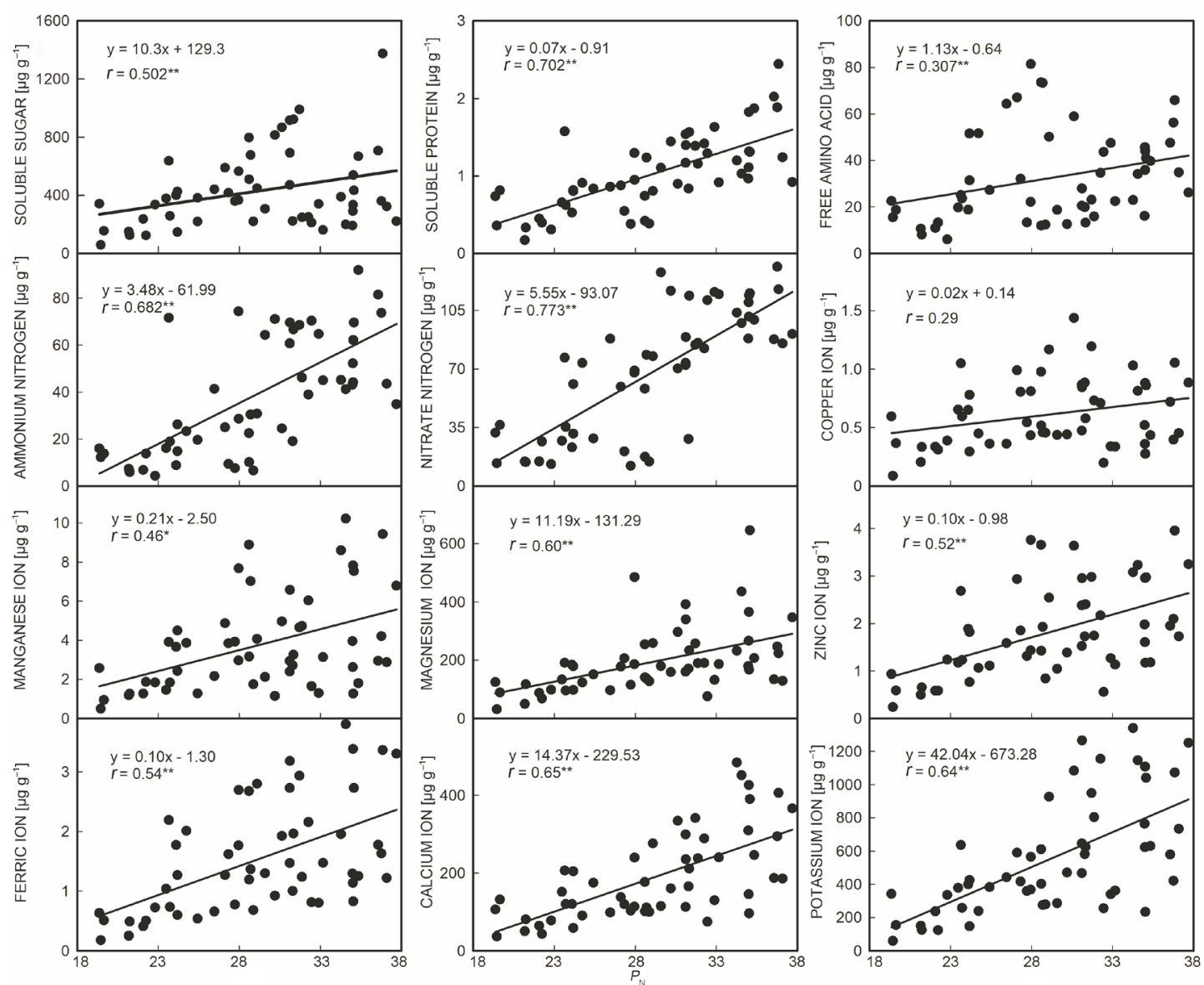

Fig. 4. Correlation between photosynthetic rate $\left(P_{\mathrm{N}}\right)$ and bleeding components among three cross combinations. Asterisks indicate significant correlation between bleeding components and $P_{\mathrm{N}}\left({ }^{*} p<0.05,{ }^{* *} p<0.01\right)$.

biomass growth through supplied mineral nutrients ( $\mathrm{Li}$ et al. 2016), which can be reflected in bleeding sap. Morita et al. (2000) pointed out that bleeding sap can be used as an effective index for the physiological activity of the whole root system in field crops. Jin et al. (1994) indicated that the bleeding-sap mass of hybrid cultivars was significantly higher than that of the corresponding parent, and that the root system of hybrids was well developed. The present study showed that BSM and most of the bleeding components had an obvious heterosis at the growth stages except for ammonium and nitrate nitrogen.

The heterosis of crop yield was mainly reflected in root development and photosynthesis. Root physiological activity had a significant positive relationship with $P_{\mathrm{N}}$, such as in soybean (Zhang et al. 2013, Cui et al. 2016), maize (Qi et al. 2007, Zhou et al. 2008), and rice (Xu et al. 2010). Cui et al. (2016) suggested that root characteristics were positively correlated with photosynthetic rate and biomass. The improvement of root characteristics may contribute to boosting of the photosynthetic efficiency, biomass, and yield. BSM could be used as an index of root physiological activity, as evidenced by the observed correlations between BSM and biomass components of plants in our study. Various nutrient components in the bleeding sap are essential for maintaining the growth of the aboveground organs. Yet, our research showed that BSM was only related to the mineral elements, but has no correlation with the nitrogen compounds and soluble sugar. Because the hybrids had a higher BSM than the corresponding parent, they may be provided with more mineral elements to maintain plant growth. Our field data indicate that not only BSM but also the bleeding components correlate positively with the $P_{\mathrm{N}}$ in maize.

The reduction of root biomass is often accompanied by decreased shoot biomass and leaf area, and it indirectly affects photosynthesis of crops (Thomas and Strain 1991). It may be a sink-limited feedback as a possible mechanism for regulating net photosynthesis, when root growth was progressively restricted. A healthy development of the root system provided mineral nutrition to elevate leaf photosynthesis; photosynthetic capacity may reach the peak value because its restrictive factors. In addition to external environmental factors, photosynthesis is also affected by the internal factors including those associated with root growth and development. When the intensity of bleeding sap and the content of bleeding components are too low, photosynthesis is inhibited. Therefore, when there were no stress factors originating from aerial environment of plants, photosynthetic capacity was a norm to identify status of root growth and development. 
Table 2. Correlation between bleeding intensity, bleeding components, and biomass per organ among three cross combinations. ${ }^{*},{ }^{* *}$ - indicate significant differences at the 0.05 and 0.01 level, respectively. DMP - dry matter per plant; HGM - hundred-grain mass; LS - leaf sheath.

\begin{tabular}{llc}
\hline Parameter & & Correlation coefficient \\
\hline Bleeding & Soluble sugar & -0.307 \\
components & Soluble protein & 0.118 \\
& Free amino acid & 0.012 \\
& Ammonium nitrogen & -0.020 \\
& Nitrate nitrogen & 0.121 \\
& Copper ion & $0.770^{* *}$ \\
& Manganese ion & $0.742^{* *}$ \\
& Magnesium ion & $0.716^{* *}$ \\
& Zinc ion & $0.711^{* *}$ \\
& Ferric ion & $0.806^{* *}$ \\
& Calcium ion & $0.782^{* *}$ \\
Potassium ion & $0.748^{* *}$ \\
& Stem & $0.655^{*}$ \\
& Leaf & $0.549^{*}$ \\
& LS & $0.523^{*}$ \\
& Ear & $0.651^{*}$ \\
& HGM & $0.581^{*}$ \\
& DMP & $0.593^{*}$ \\
\hline
\end{tabular}

\section{References}

Bao X.Y.: [Determination of nitrate nitrogen in drinking water by ultraviolet spectrophotometry.] - Chin. J. Health. Lab. Tech. 21: 1125-1126, 2011. [In Chinese]

Chairi F., Elazab A., Sanchez-Bragado R. et al.: Heterosis for water status in maize seedlings. - Agr. Water Manage. 164: 100-109, 2015.

Chen L.: [Significance and prospect of rice root breeding.] South China Agriculture 10: 151-152, 2016. [In Chinese]

Cirilo A.G., Dardanelli J., Balzarini M. et al.: Morphophysiological traits associated with maize crop adaptations to environments differing in nitrogen availability. - Field Crop. Res. 113: 116-124, 2009.

Cui X., Dong Y., Gi P. et al.: Relationship between root vigour, photosynthesis and biomass in soybean cultivars during 87 years of genetic improvement in the northern China. Photosynthetica 54: 81-86, 2016.

Dieleman J.A., Verstappen F.W.A., Kuiper D.: Bud break and cytokinin concentration in bleeding-sap of Rosa hybrida as affected by the genotype of the rootstock. - J. Plant Physiol. 152: 468-472, 1998.

FAO: FAOSTAT - Agriculture Database. Available at: http:// faostat.fao.org/, 2016.

Guan D., Al-Kaisi M.M., Zhang Y. et al.: Tillage practices affect biomass and grain yield through regulating root growth, rootbleeding-sap and nutrients uptake in summer maize. - Field Crop. Res. 157: 89-97, 2014.

Haque M.M., Pramanik H.R., Biswas J. K. et al.: Comparative performance of hybrid and elite inbred rice varieties with respect to their source-sink relationship. - Sci. World J. 2015: 326802, 2015.

Jin H., Wang G., Lu C.: [A comparative study on vigour of root system, ATPase activities and RNAase activities between maize single hybrid and its inbred parents.] - Sci. Agr. Sin. 27: 19-24, 1994. [In Chinese]

Karmakar P.G., Bhatnagar P.S.: Genetic improvement of soybean varieties released in India from 1969 to 1993. - Euphytica 90: 95-103, 1996.

Kato C., Ohshima N., Kamada H., Satoh S.: Enhancement of the inhibitory activity for greening in xylem sap of squash root with waterlogging. - Plant Physiol. Bioch. 39: 513-519, 2001.

Kimura K., Kikuchi S., Yamasaki S.I.: Accurate root length measurement by image analysis. - Plant Soil 216: 117-127, 1999.

Koester R.P., Nohl B.M., Diers B.W., Ainsworth E.A.: Has photosynthetic capacity increased with 80 years of soybean breeding? An examination of historical soybean cultivars. Plant Cell Environ. 39: 1058-1067, 2016.

Li D.Y., Zhang Z.A., Zheng D.J. et al.: Comparison of net photosynthetic rate in leaves of soybean with different yield levels. - J. Northeast Agr. Uni. (English Edition) 19: 14-19, 2012.

Li S.Y., Teng F., Rao D.M. et al.: Photosynthesis of soybean cultivars released in different decades after grafting onto record-yield cultivars as rootstocks. - Photosynthetica 55: 579-587, 2017.

Li X., Liu N., You L. et al.: Patterns of cereal yield growth across China from 1980 to 2010 and their implications for food production and food security. - PLoS ONE 11: e0159061, 2016.

Moore S., Stein W.H.: A modified ninhydrin reagent for the photometric determination of amino acids and related compounds. - J. Biol. Chem. 211: 907-913, 1954.

Morita S., Okamoto M., Abe J., Yamagishi J.: Bleeding rate of field-grown maize with reference to root system development. - Jpn. J. Crop Sci. 69: 80-85, 2000.

Muchow R.C., Davis R.: Effect of nitrogen supply on the comparative productivity of maize and sorghum in a semi-arid tropical environment II. Radiation interception and biomass accumulation. - Field Crop. Res. 18: 17-30, 1988.

Paschold A., Marcon C., Hoecker N., Hochholdinger F. et al.: Molecular dissection of heterosis manifestation during early maize root development. - Theor. Appl. Genet. 120: 383-388, 2010.

Qi J., Song F., Han X.: [Effects of drought stress on maize root and its photosynthetic physiological characteristics at seedling stage.] - J. Jilin Agr. Uni. 29: 241-246, 2007. [In Chinese]

Sedmak J.J., Grossberg S.E.: A rapid, sensitive, and versatile assay for protein using Coomassie brilliant blue G250. - Anal. Biochem. 79: 544-552, 1977.

Shi K., Ding X.T., Dong D.K. et al.: Root restriction-induced limitation to photosynthesis in tomato (Lycopersicon esculentum Mill.) leaves. - Sci. Hortic-Amsterdam 117: 197-202, 2008.

Specht J.E., Hume D.J., Kumudini S.V.: Soybean yield potentialA genetic and physiological perspective. - Crop Sci. 39: 1560-1570, 1999.

Thomas R.B., Strain B.R.: Root restriction as a factor in photosynthetic acclimation of cotton seedlings grown in elevated carbon dioxide. - Plant Physiol. 96: 627-634, 1991.

van Staden J.F., Taljaard R.E.: Determination of ammonia in water and industrial effluent streams with the indophenol blue method using sequential injection analysis. - Anal. Chim. Acta 344: 281-289, 1997.

Wang Y.Q., Xi W.X., Wang Z.M. et al.: Contribution of ear photosynthesis to grain yield under rainfed and irrigation conditions for winter wheat cultivars released in the past 30 years in North China Plain. - J. Integr. Agr. 15: 2247-2256, 2016. 
Wilcox J.R.: Sixty years of improvement in publicly developed elite soybean lines. - Crop Sci. 41: 1711-1716, 2001.

Xu M., Jia D.T., Ma D.R. et al.: [Correlation of root physiology and leaf photosynthesis characteristics in northern Chinese Japonica super rice.] - Acta Agron. Sin. 36: 1030-1036, 2010. [In Chinese]

Yemm E.W., Willis A.J.: The estimation of carbohydrates in plant extracts by anthrone. - Biochem. J. 57: 508-514, 1954.

Zhang X., Huang G., Bian X., Zhao Q.: Effects of root interaction and nitrogen fertilization on the chlorophyll content, root activity, photosynthetic characteristics of intercropped soybean and microbial quantity in the rhizosphere. - Plant Soil Environ. 59: 80-88, 2013.

Zhou H.S.: [Some thinking about the development direction of maize breeding in Liaoning province.] - In: Chinese Genetic Breeding Technology of Maize. International Symposium, ChangChun 2000. [In Chinese]

Zhou X.P., Zhang S.Q., Yang X.Q. et al.: [Heterosis of maize root activity and its relationship with photosynthetic characteristics.] - Acta Agr. Bor.-Occ. Sin. 17: 84-90, 2008. [In Chinese]

(C) The authors. This is an open access article distributed under the terms of the Creative Commons BY-NC-ND Licence. 